\title{
UNA.ESTAMPA DEL SIGLO XVI
}

\author{
$P O R$ \\ EDMUNDO O'GORMAN
}

A PROVECHANDO la oportunidad que me ofrece el Instituto de Invesborar en sus Anales, he creído oportuno publicar, juntamente con esta breve reseña, una muy interesante estampa de finales del siglo XVI, que representa a Santa Marta y cuyo original se conserva en el Archivo General de la Nación, en el Vol. 206, Doc. N\$ 9, del Ramo de Inquisición.

Por la reproducción de la pintura, *el lector podrá apreciar el interés que reviste ésta, como contribución para la historia de las Artes Plásticas en México.

La tosca ejecución, el dibujo un tanto elemental y el gusto decididamente bárbaro de la coloración, son indices claros de la procedencia popular de la obra, y es precisamente por esta circunstancia, añadida a la consideración de que se trata de una obra ejecutada hace tres siglos y medfo, por lo que la estampa en cuestión adquiere para nosotros un gran valor documental. Por otra parte, es evidente que la composición carece de originalide Anmlo Reptoducida exactamente del original en la primera lámina de este número 
dad, pues la figura de la santa está directamente inspirada, por no decir copiąda o hasta calcada, en alguna pintura o grábado de la época, y el efecto general es el de un dibujo iluminado. Por último, es de advertir que los colores empleados fueron tojo, amarillo, azul $y$ sepia con variantes de tono y el blanco. La estampa está pintada con colores de agua sobre un pliego de papel del que entonces se usaba para escribir.

Lra pintura de que se trata, aparece glosada al expediente del proceso inquisitorial fulminado contra Inés de Villalobos, mulata, por el delito de supersticiơn y hechicería. Segứn la relación de los autos, Inés de Vllalobos, residente en la Veracruz, fué mujer desenvuelta, casada con un carpintero llamado Bartolomé García, y de ella nos informa Fr. Diego de Bobadilla, Comisario del Santo Oficio en aquella población, que era "mulata de mal vivir, siempre amancebada después que se casó y muy amiga de las dos viudas Ana de Herrera y Lucía de Alcalá, que engendran sospecha".

Es el caso, que el día 12 de mayo de 1593 se presentó espontáneamenté ante el referido Comisario, una negra llamada Antonia, esclava del carpintero Garcia, a denunciar a la esposa de su amo, declarando que ésta tenía una imagen de Santa Marta a la que le rendia tun culto sospechoso, colgándola en la cama donde dormía con su marido o bien colocándola en un aposento con muchas ramas de sauce y dos candelas encendidas; que luego formaba un altar con una mesa delante de la imagen, poniendo agua bendita, pan, sal, cuchillo y manteles y también dinero; que después, desnuda la mulata, con sólo la camiśa y descabellada, decía ciertas oraciones; que el dinero lo daba a un padre para que se dijeran misas, y por último, que todo lo hacía para que su amigo, Alonso de Paz, la quisiese bien aun después de casado. Iguales cargos a los anteriores hicieron una negrita llamada Tomasina y una negra esclava, Isabel López. $\mathrm{E} 1$ : mismo día 12 de mayo, por ordén del Comisario se registró la casa de la inculpada, encontrándose en un armario la imagen de Santa Marta.

Recibidas las declaraciones y practicada la diligencia de que hemos hecho mención, el fraile consideró agotada la averiguación previa, por lo que, para la conclusión y sentenciamiento del negocio, mandó presa a México a la acusada, juntamente con el expediente de su causa, comisionando para la ejecución de esta providencia, a nadie menos que al propio mariđo de la Villulobos.

No es esta ocasión para referir todos los pormenores del proceso, por lo que nos conformamos con transcribir en seguida, como piezas más im- 
portantes, la confesión de la mulata y las contestaciones que produjo a los capítulos de acusación.

\section{(Al margen): Primera Audiencia.}

En la ciudad de México, a veinte y nueve días del mes de julio de mil y quinientos y noventa y cuatro años, estando en su audiencia de la mañana el señor Inquisidor Don Lobo Guerrero, mandó traet a ella a una mujer presa, en las cárceles secretas y recibió de ella juramento en forma y prometió de decir verdad, asi en esta audiencia como en todas las demás que con ella se tuvieren hasta la determinación de su causa, y prometió de guardar secreto en ella y de todo lo que durante su prisión oyere y entendiere, y dijo llamarse: Inés de Villalobos, mulata, natural de esta ciudad de Méxíco, Y que hasta agora se ba criado en la ciudad de Vetacruz, a donde se casó con Bartolomé García, carpintero, con quien de presente bace vida maridable, $y$ que es de edad veinte $y$ seis o veinte y siete años, poco más o menos (al margen: edad 27 affos), Y-que hoy en jueves veinte y ocho del dicho mes y año. la metieron presa en una de las cárceles secretas de este Santo Oficio, Y declató su genealogía en la forma siguiente:

Padres.--Rodrigo Franquez de Villalobos, natoral de la ciudad de Sevilla en Es paña, y Juana, criolta, morena, en quien hubo a ésta, en esta ciudad de México.

Abuejos paternos.-Dijo: que no los conoció ni oyó decir.

Abuelos maternos.-Dijo: que tampoco los conoció ni oyó decir.

Tíos hermanos de padte.-Dijo: que uno de ellos se llamaba Alonso Franquez. y marió en la Veracruz, y otro, Gonzalo Franquez, que murió en esta ciudad de Mérico.

Tíos hermanos de madre.-Dijo: que no los conoció ni oyó decir.

Hermanos de ésta, dijo: que no los ha tenido.

Hijos de ésta, dijo: que tiene dos hijos, el uno que le dice Rodrigaito, de edad de ocho meses, y una niña que se 11 ama Anita, de edad de doce años. los bubo durante el matrimonio con el dicho Bartolomé García, su marido.

Preguntada: de qué casta y generación es. (al margen: dice que desciende de cristianos viejos). Dijo: que es de cristianos viejos y que ninguno de sus padres ni ascendientes ha sido preso ni penitenciado por el Santo Oficio de la Inquisición.

(Al margen: Dijo bien las oraciones). Signóse y persignóse, y dijo fas cuatro oracíones y los diez mandamientos y la confesión bien dicha y no supo los artículos de la fe.

Preguntada: si es cristiana bautizada y confirmada, dijo: que ai y que en la Veracruz la confirmó un obispo fraile franciscano, y fué su padrino Miguel de Oñate. que ya es difunto.

Preguntada: si ba confesado y comulgado los tiempos que manda la Santa Madre Igleaia, dijo: que sí y todas las veces que hay jubileos.

Diecarso de su vida. Preguntada: por el discurso de su vida, dijo: que ella nació eth esta cindad de Mexico como tiene confesado, $y$ de aquí la llevó el dicho su padre a la Veracruz, adonde se crió en su casa labrando y cosiendo, hasta que ahora quince afios que la casó con el dicho Bartolomé García, su marido, con quién ha hecho y hace vida maridable, ocopándose en serviele como a su marido y en criar sus hijos, y que no ha ido fuera de las Indias a ningura patte, ni ha estado en reyno extraño, ni salido de la Veracruz desde que a ella la llevaron, hasta agora que la trajeton presa a esta ciadad de México, ni sabe leer ni escribir.

Preguntada: si entiende o presume la causa porqué ha sido traida presa y fo está en este Santo Oficio, dijo: que presume que ha sido traida presa porque está para libsarbe 
de la mala condición de sn marido y tener con ál paz, por consejo de Gregoria Muñiz; (al margen: contra Gregoria Muñiz) que ya es muerta; hizo una devoción a Santa Marta, y fué, que encendia una vela y hacía un altar a donde ponia a Santa Marta y enramaba el altat con unos sauces, y rezaba a la dicha Santa diez ave marías y diez pater noster, en nueve días, cada mañana, luego que su marido salía a trabajar, y decía la oración siguiente de esta manera:

Gloriosa Santa, así como fuistes querida y amada de la Vírgen Santísima y de su preciosísimo Hijo, alcancéis que no muera yo a manos de mi marido, ofendiéndoie, y para hacer esta oración se persignaba con agua bendita que hacía traer de la iglesia. $y$ después del dineto que ésta ganaba cosiendo, hacía decir unas misas (al margen: que del dinero que ganaba cosiendo hacio decir misas) por la paz de su casa y porque su marido no la hallase ofendiéndolo y que con la (al margen: porque no la hallase su marido ofendiéndole) misma agua bendita antes que viniese su marido de trabajar rociaba la casa 7 decía: of rézcote casa a Jesús Crucificado, lo cual hacía para el dicho efecto de tener paz y que el dicho su marida no la ballase ofendiéndole, lo cual hizo tres veces de dos años a esta parte. (al margen: que lo ha hecho tres veces de dos años a esta patte) mediante cato tenía paz con el dicho sa marido.

Preguntada: qué era la ofensa que ésta hacía a su marido, pues pretendia no la hahlase ofendiéndole, y para tlo hacía la oración de Santa Marta, dijo: que la ofensa que a su marido hacía era tener amistad torpe con un Alonso de Paz, que ya es casado, y que no se acuerda de otra cosa.

En la cindad de México a veinte y nueve días del mes de julio de mil y quinientos yoventa y cuatro años, estando en su audiencia de la tarde el señor Inquisidor Dr. Lobo Gnetrero, mandó traer a ella a la dicha Inés de Villalobos.

Y siendo presente, le fué dicho, que el alcaide de este Santo Oficio ha hecho telación. que pide audiencia, que en ella está que diga lo quiere $y$ la verdad, so cargo del juramento que tiene becho.

Dijo: que es verdad que ella la ha pedido para decit y manifestar que ella solía hacei una oración cuando veia un Cristo, para que ae acordase de ella, la cual enseñó a su hija. $y$ dice de esta manera:

\author{
¿A donde váis sentenciado. \\ Juez de nuestra sentencia, \\ Tus santas manos atadas \\ $Y$ tu cuerpo de inocencie? \\ Sitente y vida de sabencia. \\ Tesoro de nuestra vida \\ La ta real presencia \\ A do la lleváis escondida?
}

Mi presencia, hela aquí, Que me llevan a enclavar $Y$ cierto en aquélla Cruz Para dar al mundo laz.

¿Señor, con la pene tan terrible Llevas tu color demudado, Cómo pudo ser posible Que en ti hubiese pecado? 


\author{
Ruégote por los méritos \\ De tu Sagrada Pasión, \\ Te acuerdes de $m i$ \\ $Y$ de todos los que adoran en ti. (1)
}

Preguntada: quién la enseñó esta oración y si cree ésta que en Cristo hubo pecađo, dijo: que se la enseñaron siendo niña en la amiga, y que no cree que en Cristo haya habido pecado.

Pregentada: pues lo cree así que en Cristo no bubo pecado, como decía la dicha oracion en la cual se dice, cómo pudo ser posible que en tí hubiese pecado. Dijo: que así se la enseñaton siendo como tiene dicho niña, y que no ha advertido en lo que dice la dicha oración.

Preguntada: si ésta decía la dicha oración caando rezaba a Santa Marta, para que no la hallase su marido ofendiéndole con el dicho Alonso de la Pax. Dijor que es verdad que antes de hacer la oración de Santa Marta, para que el dicho su marido no ja matase, o la hiciése algún mal balfándola con el dicho Alonso de la Paz, rezaba la dicha oración a un Cristo, para el mismo efecto.

Preguntada: si rezaba la dicha oración también para que el dicho Alonso de 1a Paz no dejase su amistad ni se casase con otra mujer, dijo: que no hay tal.

Preguntada si cuando bacía las dichas oraciones, para los efectos dichos, creia fuesen buenas y que mediante ellas podía alcanzar lo que pretendía, que era librarse de la mala condición de su marido y que no la hallase con el dicho Alonso de la Paz, au amigo. (Al margen: Que entendió que ecan buenas las oraciones) Dijo: que si, que lo creyo, y que entiende que mediante haberlas dicho su marido no la halló con el dico Alonso de la Paz. Y no tiene más que decit, y con esto amonestaba que diga la verdad, fué mandada llevar a su cárcel; y en esto se hincó de rodillas y con muchas lágrimas pidjó se nse con ella de misericordia, leyósele esta su declaración, y la aprobó y firmó por ella el señot Inquisidor.

\author{
E1 Dr. Lobo Guerrero. (Rúbrica.) \\ Pasó ante mí. \\ Pedro de Mañozca. Srio. (Rúbrica.)
}

\title{
(A1 margen: Juramento)
}

Y asi presentada y leída la dicha acusación, fué recibido juramento, en forma debida de derecho de la dicha Inés de Villalobos, so cargo del eual prometió de decir verdad $Y$ respondiéndo. (Al margen: Capitulo 19) al primer capítulo de la dicha acusación que le fué vuelta a leer:

Dijo: que ella es cristiana, bautizada y confirmada, y que suertes no las ba hecho en su vida.

(Al margen: Capitulo 20) Al segundo capítulo, dijo: que es verdad que elia dijo ta oración de Santa Marta como lo tizne confesado, y no de la manera que el capítulo de la acusación dice, y asi mismo la oración adonde va señalado etc., (al margen: dijo la otación para que su amiga la quisiése bien y no la olvidase) en la forma que tiene dicha, para que el dicho su marido no la cogiese con su amigo, y también para que el dicho sn amigo la quisiése bien y no la olvidase, y que si no lo ha dicho hasta aquí el haber dicho la oración para que su amigo la quisiese bien, fué por no haberse acordado, (al margen: se levontaba en faldetlin y destocada y encendía la vela) y que es verdad que se levantaba prosa.

(1) En el MS, no viene la otación en cuartetas, sino seguidos los versos como 
de la cama para hacer las dichas oraciones en faldellin y destocada, y que para haber de hacer las dichas oraciones encendía una vela de cera y no dos como dice el capirulo, (al margen: del dinero mandaba decir misas) y que lo del dinero que casualmente lo metía en el altar, y que es verdad que dél mandaba decir misas a la Pasión de Jesucristo y a Santa Marta, (al margen: que no la olvidase su amigo y la quisiése bien) y a otros santos, para que el dicho sa marido no la hallase ofendiéndole con el dicho su amigo, y para que no la olvidase el dicho amigo y la quisiése bien.

(Al margen: Capitulo 3P) Al capitulo cercero. Dijo: que ya tiene confesado que es cómo mandaba decir misas del dicho dinero para el efecto dicho, y que es verdad que créa que mediante el dicho sacrificio so marido no la babía de hacer mal, ni ballar ofendiéndole como en efecto no la balló. (A1 margen: Créio que mediante el sacrificio su amigo la quertía bién y no la olvidaria) $Y$ también creía que mediante el tal sacrificio su amigo la quertia bien y no la olvidaría, an que más créa lo que toca al dieho su marido.

(Al margen: Capitulo 40) Al capítulo cuarto. Dijo: que lo niega y que solamente decia cuando venía su marido, of rézcote a Jesucristo Crucificado, que me defienda de tí $y$ de todo mal.

(Al margen: Capitulo 59) Al capitulo quinto. Dijo: que lo niega.

(Al margen: Capitulo 69) Al capítulo sexto. (Al margen: que enviaba por la agua y la echaba sobre Santa Manta) Dijo: que es verdad que enviaba a San Francisco por agua bendita, y la echaba sobre el altar y imágen, antes de decir las oraciones para los efectos que tiene declarados, y que se acuerda, que cuando decía la oración de Santa Marta, decía después de haberla acabado. (al margen: por que el amigo la quisiése bien y no la olvidase aunque se casase) Así como soís querida y amada de la Vírgen Santísima y de Nuestro Señor Jesucristo, os ruego alcancéis de mi Dios y Señor que no muera yo a manos de mi marido. y que éste hombre me quieza bien $y$ no me olvide, aunque se case.

(Al margen: Capitulo 7\%) Al capítulo séptimo, Dijo: con lágrimas y pidiendo misericordia, que bien entiende de que el demonio la engañó y anda en semejantes cosas que éstas, y que no siente mal de la $\mathrm{fe}$, y que no ba cometido otros delitos, ni ha dejado de declarar cosa ninguna de lo que se actuerda, y aunque le den tormento no dirá mas de lo que tiene confesado.

E1 dicho señor Inquisidor le mandó dar translado de la dicha acusación y que responda a ella con parecer de letrado.

(Al margen: Nonbramiento de Abogado) Y siéndole nombardos los letrados que en este Santo Oficio ayuden a los reos, nombró, por su abogado al Lic. Juan Nañez.

$Y$ con esto amonestada, fué mandada llevar a su cárcel, $y$ siéndole leídas estas sus respuestas, las aprobó y firmó por ella el señor Inquisidor.

EI Dr. Lobo Guertero. (Rúbrica.)

Pasó ante mí.

Pedro de Mañoza, Srio, (Rúbrica.)

Como resultado final de los procedimientos, una vez votada la causa, los inquisidores dictaron sentencia en la que, Inés de Villalobos fué declarada culpable como supersticiosa, debiendo salir a oír el fallo, con vela de cera en las manos y coroza blanca en la cabeza, en el Auto Público de la Fe que se preparaba para el día 8 de diciembre de 1596 (2) y que en efecto se celebró

(2) Fué este Auto uno de los más sonados: se recordará que en él salió, entre otros judios, Luis de Carbajal el mozo. También salieron, por hechicetas, Ana de $\mathrm{He}$ rrera y Lucía de Alcalá, amigas de la Villalobos. 
ese dia, con gran solemnidad en la Plaza Mayor de la Ciudad de México. Inés resultó condenada a abjurar de levi; a pagar cien pesos de oro común, y a sufrir destierro de la Ciudad de México y de Veracruz por espacio de un año.

Tales son, en resumen, Jos hechos consignados en el proceso donde existe como pieza de autos la curiosa estampa que ha motivado estas líneas. Por nuestra parte, enterados ya de su historia, no podemos menos que sentir un vivo interés al contemplar la pintura, no ya solamente como un ejemplo curioso de la imaginería mexicana del siglo XVI, sino como la imagen que tanto significó a una mujer, quien, con todo el valor humano de la superticiosa confianza que en ella puso, la veía como el medio eficaz para retener el prohibido amor del amigo que bien quería. 